\title{
A MORAL COMO PROBLEMA EM KANT ${ }^{1}$
}

\author{
Joãosinho Beckenkamp \\ Universidade Federal de Pelotas
}

\begin{abstract}
For most readers of Kant's moral philosophy, Kant seems to be an avatar of morality, the great preacher of the categorical imperative. This paper aims to show that for Kant himself morality is after all a problem to be solved by philosophy.

Keywords: Morality, Kant, criticism, problem.

Resumo: A leitura mais usual da filosofia moral kantiana encontra em Kant mais um avatar da moralidade, o grande moralista que brindou a humanidade com seu imperativo categórico. 0 presente artigo procura mostrar que para Kant a moralidade constitui antes de mais nada um problema a ser resolvido pela filosofia.
\end{abstract}

Palavras-chave: Moral, Kant, criticismo, problema.

Para o povo em geral, a moral constitui como que a atmosfera em que se vive sem nunca se aperceber de sua presença. No máximo, alguém imerso nestas massas humanas chega a ter uma opinião sobre valores e juízos morais, seus ou dos outros. A grande diferença de valoração que vai de uma passeata de protesto contra os maus tratos fatais infligidos a uma cadela prenhe, de um lado do planeta, até o hábito de comer cachorros, gatos e qualquer bicho que estiver ao alcance, do outro lado do planeta, esse grande leque de variações não chega a ser percebido pelo indivíduo do povo. Valores morais são como o ar que se respira: não constituem um problema.

Para o filósofo, entretanto, e isto desde a sua invenção pelos gregos, a moral constitui um objeto preferencial de sua reflexão, chegando mesmo, na época moderna, a se tornar um problema que desafia o pensador crítico. Sem a referência de uma bela cidade, pela qual valeria a pena sacrificar a própria

\footnotetext{
1 Texto de palestra proferida no Colóquio "Temas de Ética e Filosofia Política", promovido pelo Programa de Pós-Graduação em Filosofia da Universidade Federal de Pelotas.
} 
vida se necessário, sem a referência de uma vontade divina, cujo castigo eterno seria melhor prevenir, sem referência além de si mesmo, o pensador moderno se depara com um grande problema quando tenta indicar o fundamento de nossos valores e juízos morais, que ameaçam doravante resvalar para a vala comum dos preconceitos populares. De Hume a Nietzsche, a moral está sob suspeita; na melhor das hipóteses, ela logra colocar-se como um problema a ser enfrentado pelo pensamento filosófico com o rigor de sua crítica e de seu método.

No concernente a Kant, sua fama de moralista e cavaleiro da triste figura dos discursos éticos sem fundamento é tão grande, que muitos de seus leitores sequer percebem que para ele a moral constitui antes de tudo um problema a ser enfrentado pelo filósofo. Diferentemente de Nietzsche, que resolve o problema afundando a moral no pântano das valorações sem fundamento, retraçando-lhe a genealogia pouco nobre, Kant se esforça para responder ao problema com um programa de fundamentação racional da moral, quiçá o mais ambicioso já concebido.

Um programa infelizmente não implica o sucesso em sua execução. Assim, a moral comparece como problema em dois momentos capitais da leitura dos textos kantianos dedicados à filosofia moral. Em primeiro lugar, a moral constitui efetivamente um problema para Kant mesmo, momento que nos interessa mais de perto aqui. Mas, em segundo lugar, a moral continua um problema depois da execução do programa de fundamentação racional concebido por Kant, pois é altamente questionável se a exposição dos diversos argumentos encontrados na Fundamentação da metafísica dos costumes e na Crítica da razão prática realmente estabeleceu algo além da impressão de que a moral parece afinal não ter fundamento. Tudo se passa como se Kant não tivesse conseguido ir além de produzir a crise da moral, no sentido antigo e médico do termo.

A irrupção desta crise se torna inevitável a partir do momento em que Kant recusa as alternativas modernas de fundamentação da moral, que funcionam na verdade como paliativos que impedem o claro diagnóstico da falta de fundamento: "Basta olhar os ensaios sobre a moralidade naquele gosto preferido, que logo encontraremos, ora a determinação particular da natureza humana (mas por vezes também a idéia de uma natureza racional em geral), ora a perfeição, ora a felicidade, aqui o sentimento moral, acolá o temor de Deus, um pouco disto, mais um pouco daquilo, numa mistura 
espantosa" (GMS, AA IV, 410). ${ }^{2}$ A grande confusão reinante na literatura moral moderna provém em boa medida do fato de se ter a experiência como ponto de partida da filosofia moral, quando, na visão de Kant, "é simplesmente impossível estabelecer com toda certeza pela experiência um único fato sequer no qual a máxima ter-se-ia baseado apenas em fundamentos morais" (GMS, AA IV, 410). O flerte com a experiência na filosofia moral apenas faz esquecer o rigor das exigências implicadas nos juízos morais mais comuns, evitando assim que seja colocada a questão de seu fundamento. Terreno propício para o ceticismo, de outro lado, pois, sendo tudo relativo na moral, tudo é igualmente destituído de fundamento sólido e racional. $\mathrm{O}$ empirista em filosofia moral presta um grande serviço àqueles que vêem na moral uma simples idiossincrasia, um mero preconceito dos povos, uma quimera: "Não se pode prestar um serviço mais desejável àqueles que ridicularizam toda moralidade como simples quimera de uma imaginação humana que se excede por presunção, do que lhes conceder que os conceitos do dever tiveram de ser tirados meramente da experiência; pois então se lhes prepara um triunfo seguro.” (GMS, AA IV, 407). Olhando para o cenário da filosofia moral de seu tempo, Kant vê claramente que a moral em sentido estrito e rigoroso se tornou um problema, sendo mais possível argumentar pela tese de que a moralidade não passa de uma simples quimera de uma humanidade que não consegue se ater humildemente a seus limites e então sai a imaginar Deus, imortalidade, moralidade etc.

É claro que, se em filosofia moral a experiência leva ao relativismo e mesmo ao ceticismo, será preciso abandonar o campo da experiência e ensaiar uma fundamentação com base na razão pura, ou seja, empreender finalmente aquilo que Kant chama de metafísica dos costumes. Se o filósofo quiser mostrar que a moral é possível, quer dizer, que suas valorações e exigências não são absurdas porque meramente quiméricas, terá de levar a sério então a descoberta de que, ou se admite que as representações morais não passam de quimeras sem fundamento racional, como tem de fazer todo empirista, ou se parte do princípio de que "todos os conceitos morais têm seu lugar e sua origem inteiramente a priori na razão” (GMS, AA IV, 411). A segunda seção da Fundamentação da metafísica dos costumes faz

2 São empregadas aqui as seguintes abreviações: GMS - Grundlegung zur Metaphysik der Sitten (Fundamentação da metafísica dos costumes), citada pela edição da Academia Prussiana de Ciências (AA, seguido de volume e página); e KpV - Kritik der praktischen Vernunft (Crítica da razão prática), citada pela primeira edição $(A)$. 
precisamente a transição para esta ordem da conceituação puramente racional na moral, partindo da representação popular de um dever moral irrecorrível para, através de uma regressão simplesmente analítica, chegar àquela travação conceitual da razão capaz de sustentar uma exigência incondicional como a que se encontra em toda moral efetiva. $\mathrm{O}$ resultado principal desta análise é a exposição de um imperativo categórico da razão que, subjazendo a toda noção de dever moral em sentido estrito, logra finalmente conferir um sentido racional a esse dever. De brinde, a análise oferece ainda a fórmula deste imperativo, uma fórmula depois tornada tão popular quanto as máximas moralizantes do nazareno. Seja-me poupada sua repetição.

Tarefa realizada, resolvido o problema da moral? Longe disto, pois Kant sabe muito bem que uma proposição obtida pela análise de algo pressuposto só constitui um verdadeiro fundamento na demonstração se puder ser demonstrada ela mesma, o que na terminologia kantiana se chama "dedução". Começa então já na segunda seção da Fundamentação da metafísica dos costumes a odisséia kantiana da dedução do imperativo categórico. Mesmo antes de apresentar sua famosa fórmula, Kant reconhece que a maior dificuldade será precisamente mostrar como um tal imperativo é possível: "como um mandamento assim absoluto é possível, mesmo que conheçamos seus termos, ainda exigirá um esforço particular e pesado, que entretanto deixamos para a última seção.” (GMS, AA IV, 420). Antes da demonstração do princípio que deve servir de fundamento à ordem do dever, a moral continua, pois, um problema, vendo-se Kant constrangido a deixar indecidido, mesmo depois de enunciada a fórmula do imperativo categórico, "se aquilo que se chama dever não é afinal um conceito vazio" (GMS, AA IV, 421). Lembre-se que a expressão "conceito vazio" está em Kant para tudo o que não tem fundamento, carece de objetividade ou manifesta parentesco com o simplesmente quimérico. Ter de admitir que talvez o dever moral não passe de um conceito vazio é o mesmo que admitir que talvez a moral não tenha afinal nenhum fundamento, ou seja, que podem ter razão aqueles que a ridicularizam como uma quimera de uma imaginação humana excessivamente fantasiosa e vaidosa.

Algumas páginas adiante, Kant volta às protelações: "Mas ainda não estamos em condições de demonstrar a priori que um tal imperativo efetivamente ocorre, que há uma lei prática que ordena absolutamente e sem quaisquer móbeis e que o cumprimento desta lei é dever.” (GMS, AA IV, 
425). Mais algumas páginas, e o problema continua em pé: “A questão é, portanto, se constitui uma lei necessária para todos os seres racionais julgar sempre suas ações segundo máximas tais que possam querer que sirvam de leis universais” (GMS, AA IV, 426). Já sabemos que só uma metafísica dos costumes terá ainda uma chance de responder afirmativamente a essa questão. Mas a resposta demora, é anunciada, protelada e intercalada por outros tantos excursos analíticos. Os leitores de Nietzsche sabem que se trata de um truque retórico ou literário quando esse faz seu Zaratustra protelar sempre de novo o enunciado do igualmente famoso princípio do eterno retorno. As protelações de Kant parecem antes um indício de que efetivamente lhe falta a resposta, algo que o leitor acabará constatando se concluir a leitura da Fundamentação da metafísica dos costumes e da Crítica da razão prática. Kant sabe que a moral se tornou um problema; em sua análise mostra ademais que a única solução possível se encontra numa metafísica dos costumes que expõe finalmente o que pode constituir o fundamento das exigências morais. Só que aquilo que pode constituir o fundamento da moral não o faz efetivamente a não ser que seja por sua vez racionalmente fundamentado, quer dizer, demonstrado ou deduzido. Para tanto, é preciso demonstrar a possibilidade de que "a razão por si só determina o comportamento" (GMS, AA IV, 427).

Portanto continua o problema: "se todo valor fosse condicionado, por conseguinte contingente, não seria possível encontrar em geral nenhum princípio prático supremo para a razão" (GMS, AA IV, 428-9); "se, portanto, deve haver um princípio prático supremo e, em vista da vontade humana, um imperativo categórico, então tem de ser tal que...” (GMS, AA IV, 429). E segue-se novo excurso meramente analítico. Algumas páginas adiante, o leitor é surpreendido pela declaração de que os imperativos da moral "só foram admitidos como categóricos porque se tinha de admitir algo assim no caso de se querer esclarecer o conceito de dever" (GMS, AA IV, 431), com o que estamos simplesmente de volta ao início! O que está plenamente em ordem, já que a segunda seção da Fundamentação da metafísica dos costumes não visava demonstrar a validade da lei ou do imperativo, como volta a ser lembrado mais para o fim da seção: "este empreendimento não cabe, entretanto, à presente seção” (GMS, AA IV, 440). A segunda seção encerra coerentemente com a declaração de que era meramente analítica, contando com um leitor que admite que a moral não é uma quimera: "Quem, portanto, tem a moralidade como algo, e não como uma idéia quimérica sem 
verdade, precisa conceder igualmente o exposto princípio da mesma.” (GMS, AA IV, 445). Mas esse princípio da moralidade não pode por sua vez ser estabelecido analiticamente, tratando-se de um juízo sintético.

Como juízo sintético, e na verdade a priori, visto que não derivável da experiência, o imperativo categórico exige uma demonstração ou dedução que estabeleça sua verdade. Essa demonstração não tinha sido fornecida até o fim da segunda seção da Fundamentação da metafísica dos costumes, como Kant deixa bem claro: "Como uma tal proposição prática sintética é possível a priori e porque ela é necessária, isso constitui uma tarefa cuja solução já não se encontra dentro dos limites da metafísica dos costumes, tampouco afirmamos aqui sua verdade, muito menos pretendemos ter em nosso poder uma demonstração sua.” (GMS, AA IV, 444-5). A esta altura, o leitor está ansioso para ver finalmente a dedução prometida, mas o que recebe é um novo exercício preparatório, como Kant parece ter entendido a terceira seção da Fundamentação. A segunda seção encerra com uma pungente declaração do fato de que a moral continua sendo um problema não resolvido: "Agora, que a moralidade não é uma quimera, algo que se segue se o imperativo categórico for verdadeiro e simplesmente necessário como um princípio a priori, isso requer um possível uso sintético da razão prática pura, uso que não devemos arriscar, entretanto, sem o fazer preceder de uma crítica desta mesma faculdade da razão, da qual temos de apresentar na última seção os traços principais suficientes ao nosso propósito.” (GMS, AA IV, 445). Ou seja, a solução prometida do problema da moral não só não foi oferecida na segunda seção, como parece não ter sido prevista na terceira.

$\mathrm{O}$ que se publicou até hoje sobre a desastrada terceira seção da Fundamentação da metafísica dos costumes já custou muitas florestas e provavelmente ainda custará outras tantas. Pois muitos dos leitores de Kant procuram nela exatamente a demonstração prometida, acabando profundamente decepcionados ao se depararem com um dos textos mais confusos da obra de Kant. Se Kant realmente tentou uma dedução do imperativo categórico nesta seção, terá sido seu único empreendimento essencialmente fracassado; nisso concordam a maioria de seus leitores. Se esse foi o caso, Kant mesmo terá reconhecido seu fracasso, já que apenas três anos depois publica sua Crítica da razão prática com a afirmação categórica de que uma tal demonstração é impossível. A crer na colocação final da segunda seção, entretanto, o propósito de Kant não era oferecer propriamente uma 
dedução do imperativo categórico, mas apenas lhe preparar o terreno por meio de uma crítica da razão prática pura.

Seja como for, ao redigir sua segunda Crítica, Kant continua tendo a moral como um problema a ser resolvido pelo filósofo. O problema está claro, assim como está claro agora que Kant ainda não o resolveu definitivamente. Por isto, é preciso voltar ao início. O argumento da Crítica da razão prática começa conseqüentemente com uma análise dos conceitos e princípios envolvidos na determinação da vontade. A própria vontade continua sendo entendida como a capacidade de agir segundo a representação de uma regra. Se essa regra tem validade apenas para o indivíduo que a segue, constitui meramente uma máxima. Se pode ser reconhecida como válida também pelos demais seres racionais, a regra constitui um princípio, que pode ser condicionado, se pressupõe um objeto da vontade como condição de sua validade, ou incondicionado, se prescreve sem nenhuma condição, fim ou objeto da vontade. É em torno deste último tipo de regras que se coloca então o problema da moral. A análise kantiana mostra que as exigências rigorosas da moral só podem ser racionalmente fundamentadas se a razão prática puder determinar a vontade como razão pura, outorgando-lhe uma lei originária da pura razão. Eis a questão nas palavras de Kant: "Se admitirmos que a razão pura pode conter um fundamento praticamente suficiente, i. é, suficiente para a determinação da vontade, então existem leis práticas; do contrário, todos os princípios se tornam simples máximas" ( $K p V, \mathrm{~A} 35-36)$. A questão é a mesma que Hume respondeu negativamente em seu Tratado da natureza humana, afirmando que a razão não pode determinar a vontade por si só, sendo sempre apenas serva das paixões.

Para enfrentar o problema fundamental da moral e mostrar que a razão pura pode, sim, constituir um fundamento suficiente para a determinação da vontade, a Crítica da razão prática despede antes todas as alternativas, ou seja, todos os princípios determinantes da vontade que pressupõem um objeto ou fim. Esses princípios chegam no máximo a um egoísmo bem ordenado e administrado. É esta a tarefa dos $\S \S 2$ e 3 , inclusive suas longas notas. O princípio que se candidata a princípio da moral tem de ser, por conseguinte, um princípio concernente simplesmente à forma na determinação da vontade, como explicita o $\S 4$. Será um princípio que estipula algo em relação à forma das máximas. Feitas estas análises introdutórias, o enunciado deste princípio pode ser obtido respondendo a 
dois problemas em sentido técnico-geométrico, tarefa dos $\S \S 5$ e 6 . Problema I: "Supondo-se que a simples forma legisladora das máximas é por si só o fundamento suficiente de determinação de uma vontade, encontrar a constituição daquela vontade que é assim determinável exclusivamente.” ( $K p V$, A51). Na resolução deste problema, o filósofo é obrigado a postular o que há de mais problemático na metafísica moderna, a saber, que a única vontade capaz de suportar as exigências da moral é uma vontade livre, isto é, uma vontade capaz de se determinar independentemente de toda afecção natural. Esta capacidade, entretanto, é explicitamente recusada em toda a tradição empirista, da forma mais enfática por Hume. Ou seja, Kant aqui responde a um problema com a postulação de algo que é mais problemático ainda.

Problema II: "Supondo-se que uma vontade é livre, encontrar a lei que é apta para por si só determiná-la de maneira necessária.” ( $K p V$, A52). Supondo-se que a vontade seja livre...: é claro que Kant tem plena consciência de que se move no campo minado dos problemas metafísicos. Aliás, no essencial toda a sua filosofia crítica é destinada a fazer frente a estes problemas, particularmente aquele da liberdade. A pressuposição da liberdade não é, portanto, nada indiferente. Mas é assim mesmo que se procede na fase analítica de um argumento por análise e síntese. Aliás, a segunda seção da Fundamentação da metafísica dos costumes fez o mesmo, partindo de uma vontade livre ou autônoma para descobrir sua lei, ou melhor, a fórmula de sua lei. A fórmula que é finalmente apresentada no $\S 7$ é o nosso velho imperativo categórico.

Para nós já ficou claro, entretanto, que o problema principal da fundamentação kantiana da moral não reside na formulação do imperativo da moralidade, mas em sua demonstração. Ora, Kant surpreende seu leitor cheio de expectativa com a célebre declaração de que a lei moral é um fato da razão (cf. $K p V$, A56s), mais ainda, um fato inegável (cf. $K p V$, A56), tão fato, que não carece de nenhuma demonstração: "a realidade objetiva da lei moral não pode ser demonstrada por nenhuma dedução, por qualquer esforço da razão teórica, especulativa ou empiricamente apoiada, e ainda assim permanece firme por si mesma.” ( $K p V$, A81-2).

O fato da razão também começa a cobrar suas florestas, porque afinal os kantianos nunca vão se resignar com a constatação de que, depois de ter mostrado com uma clareza e insistência sem precedentes que a moral constitui antes de mais nada um problema para o filósofo, depois de ter 
mostrado ademais o que se deve esperar de uma solução desse problema, ou seja, a demonstração da realidade objetiva da lei moral, Kant declara solenemente que seria pedir demais exigir uma tal demonstração. Então, em vez de aceitar o fato de que Kant nos ficou devendo a demonstração decisiva no seu programa de fundamentação racional da moral, o bom kantiano prefere acreditar que na tese do fato da razão se esconde uma intuição genial de Kant que até hoje ainda não foi penetrada, mas que um dia alguém há de penetrar, colhendo provavelmente os louros da imortalidade!

Dos dois momentos em que a moral se apresenta como um problema em Kant, parece-me que o mais importante é efetivamente o primeiro, ou seja, sua contribuição para expor claramente o que constitui o problema da moral em geral. No que diz respeito ao segundo momento, se seus esforços são bem sucedidos ou não, creio que fica a juízo de cada um de seus leitores decidir se depois dele o problema deve ser considerado resolvido ou se, como foi sugerido aqui, a moral continua sendo um problema filosófico sem solução.

E-mail: joao.beckenkamp@yahoo.com

Recebido: outubro/2007 Aprovado: dezembro/2007 